\title{
Conclusions of the BioValley MedTech Day, Thursday 21 October 2004
}

\author{
Jean-François Roth*
}

\begin{abstract}
Jean-François Roth, president of the government of the Republic and Canton of Jura, in his conclusions at the MedTech Day in Basel of the BioValley Life Sciences Week, emphasized the importance his canton attributes to being tied to the Life Sciences environment of Basel and the BioValley. The canton of Jura, lying in the southern-most part of the BioValley, has a strong tradition in watchmaking which later branched out into microtechnology, an industry which requires precision and meticulousness. Therefore, there is a strong relationship between microtechnology and life sciences and more specifically, medical technology. Since medical technology is a fast growing business area, the Canton of Jura took the strategic decision to place the support of this industry at the centre of its economic development plans.
\end{abstract}

Keywords: Canton of Jura · Economic development · Life sciences · Medical technology · Microtechnology, Technology transfer

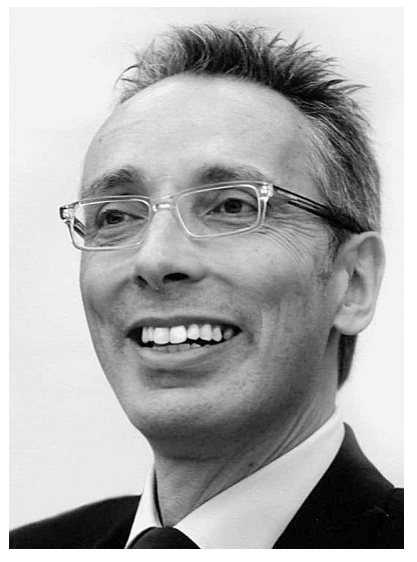

${ }^{*}$ Correspondence: J.-F. Roth

Minister of Economy and Cooperation of the

Republic and Canton of Jura

12 Rue de la Préfecture

$\mathrm{CH}-2800$ Delémont

Tel.: +4132420 5200

Fax: +4132420 5201

E-Mail: bde@jura.ch
I have the honor to draw the conclusions of today's BioValley MedTech Day and the conferences that you have been able to attend throughout the day. As an opening remark, I would like to explain why the Minister of Economy and Cooperation of the Republic and Canton of Jura is presenting these conclusions. Certainly it is not because the Jura has any illusions about being at the top of research in this field, nor that my canton believes it has the best companies in this area. Nor is it because our economy is in such a poor state of health that we need to come here looking for solutions where the best remedies in the world are produced.

No, the reason why the Canton of Jura is present at such an event is due to a political decision it has taken concerning the economic development, which seems to me, corresponds to a major industrial tendency in the Jura. This industry, as you well know, has its roots in watchmaking which later developed into microtechnology, an industry which presupposes precision and meticulousness. Therefore, there is a strong relationship between microtechnology and life sciences and more specifically, medical technology. It is this very synergy which we wish to reinforce by bringing the Jura closer to the Basel area and, quite simply because we are neighbors. The microtechnology industry in the Jura has a growing interest in medical technology which will translate into political action: one of the three main objectives of the program for economic development includes strengthening the relationship between micromechanics and life sciences.

The economy of the Jura is thus at the beginning of a process. I would like to make a point in thanking the organizers of the conferences for contributing to this process. There is no doubt in my mind that the Jurassic companies will benefit from their attendance at the BioValley Life Sciences Week.

Throughout the day you have witnessed the many advances in technology which characterize biomechanics and prosthetics, as well as the possibilities which are open to us. Life sciences are without a doubt one of the most fertile areas of fundamental and applied research. At the same time, life sciences deeply influence the evolution of many other economic areas either directly in the production of goods needed to satisfy our growing needs (pharmaceuticals, medical and paramedical services), or indirectly through investment, laboratory equipment, medical tools, etc.

In this context, the transfer of technology - and by this I mean the transformation of research results into economic goods plays a vital role. Not only because the resulting economic activities create qualified jobs, but also because these activities point the way to future research. It is certainly safe to affirm that if research is essential for economic activity, likewise research needs the market to develop, because the market provides the funds necessary to finance research, as it provides research with the in- 
formation needed to continue in the proper direction.

At the roundtable a few moments ago the problem of general conditions which influence economic activity and consequently research was mentioned. It is clear that the state has an important role to play here which is not always very well perceived. It is certainly a good thing to avoid blocking the development of biotechnology with regulations, but stimulating research and technology transfer is even better.

The state is often called upon to improve general economic conditions. The general conditions referred to, however, often are only a part of a complex set of factors which authorities can only partly influence. Some of these, as for instance taxes, are part of a larger picture which needs to be kept coherent. Above all, in order to apply a judicious policy intended to improve general conditions, it is important to precisely identify all the variables and reasonably evaluate the depth of action. These two factors seldom coincide and action is usually taken too late, if at all.

This question brings me back to the situation in the Canton of Jura where the economy is mainly comprised of SMEs, quite similar to the ones referred to at the roundtable. With the firm intent to encourage these companies and at the same time improve general conditions in the Jura, the government has taken a number of measures:
First of all, on May 16, 2004, the people of the Jura approved a government motion to reduce taxes substantially by $20 \%$ over the next 20 years for private persons and enterprises on the basis of $5 \%$ as of this year and then $1 \%$ every year until 2020. This drastic tax reduction, unique in Switzerland, will considerably improve the tax conditions in the Jura and will force the canton and the municipalities to rigorously manage public finances. I would like to emphasize the fact that the government proposed this tax reduction with a long-term view, so that it is credible in the eyes of an investor. It will be of no use to improve general conditions today if it is only to regress tomorrow should the pressure become too great. The best general conditions are those which are sustainable in the eyes of an investor.

Secondly, the government is committed to facilitating investments by enterprises starting out in life sciences, particularly in the medical technology field. This means that Jurassic enterprises will receive financial support to enable them to acquire status as a life sciences supplier.

Thirdly, the government has the intention to create a fund for professional training. This fund will be financed by modest employer contributions. This fund will allow employees to acquire professional competences required by companies working in the field of life sciences.

Finally, the Canton of Jura will establish within the next few weeks a competence network centered around people presently involved in research. Eligible are people who have a project to create an economic activity or who are now working on such a project. These projects, primarily those related to life sciences, will be vigorously supported logistically and financially by the state. An incubator designed for projects in the field of life sciences will soon be created in Delémont.

This is the simple but targeted strategy put in place by our government. I am convinced that it will lead to positive results. In any event, the government intends to strengthen the bond between the industries of microtechnology in the Jura and life sciences in the Basel area.

The speakers of today's MedTech Day have shown the genius which lies in medical technology and in life sciences in general. I am convinced that this type of encounter is essential. It is essential for the specialists who are given the opportunity to compare their contributions in this field and for the novice such as me who is given the opportunity to marvel at this science. I would like to congratulate the people who have contributed to this day. I thank BioValley AG, BioValley, Messe Schweiz, KPMG, the organizers and partners of this day. I thank all of you who have enriched this day by your presence.

Received: October 25, 2004 